\title{
Models and methods to characterise levonorgestrel release from intradermally administered contraceptives
}

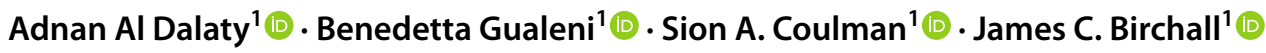

Accepted: 1 November 2021 / Published online: 3 December 2021

(c) The Author(s) 2021

\begin{abstract}
Microneedle (MN)-based technologies have been proposed as a means to facilitate minimally invasive sustained delivery of long-acting hormonal contraceptives into the skin. Intradermal administration is a new route of delivery for these contraceptives and therefore no established laboratory methods or experimental models are available to predict dermal drug release and pharmacokinetics from candidate MN formulations. This study evaluates an in vitro release (IVR) medium and a medium supplemented with ex vivo human skin homogenate $(\mathrm{SH})$ as potential laboratory models to investigate the dermal release characteristics of one such hormonal contraceptive that is being tested for MN delivery, levonorgestrel (LNG), and provides details of an accompanying novel two-step liquid-liquid drug extraction procedure and sensitive reversed-phase HPLC-UV assay. The extraction efficiency of LNG was $91.7 \pm 3.06 \%$ from IVR medium and $84.6 \pm 1.6 \%$ from the medium supplemented with SH. The HPLC-UV methodology had a limit of quantification of $0.005 \mu \mathrm{g} / \mathrm{mL}$ and linearity between $0.005 \mathrm{and} 25 \mu \mathrm{g} /$ $\mathrm{mL}$. Extraction and detection methods for LNG were exemplified in both models using the well-characterised, commercially available sustained-release implant (Jadelle $\left.{ }^{\circledR}\right)$. Sustained LNG release from the implant was detected in both media over 28 days. This study reports for the first time the use of biologically relevant release models and a rapid, reliable and sensitive methodology to determine release characteristics of LNG from intradermally administered long-acting drug delivery systems.
\end{abstract}

Keywords Levonorgestrel $\cdot$ Skin $\cdot$ Microneedles $\cdot$ Intradermal $\cdot$ Contraception $\cdot$ Method

$\begin{array}{ll}\text { Abbreviations } \\ \text { ACN } & \text { Acetonitrile } \\ \text { AUC } & \text { Area under curve } \\ \text { EC } & \text { Extraction control } \\ \text { DMEM } & \text { Dulbecco's modified Eagle's medium } \\ \text { FDA } & \text { US Food Drug Administration } \\ \text { ICH } & \text { International Council for Harmonisation } \\ \text { IVR } & \text { In vitro release medium } \\ \text { LARC } & \text { Long-acting reversible contraceptive } \\ \text { LC-MS } & \text { Liquid chromatography-mass spectrometry } \\ \text { LLE } & \text { Liquid-liquid extraction } \\ \text { LNG } & \text { Levonorgestrel } \\ \text { LOD } & \text { Limit of detection } \\ \text { LOQ } & \text { Limit of quantification } \\ \text { MN } & \text { Microneedle } \\ \text { PBS } & \text { Phosphate-buffered saline } \\ \text { PPT } & \text { Protein precipitation }\end{array}$

James C. Birchall

birchalljc@cardiff.ac.uk

1 School of Pharmacy and Pharmaceutical Sciences, Cardiff University, Cardiff CF10 3NB, UK

$\begin{array}{ll}\text { RE } & \text { Relative error } \\ \text { RIA } & \text { Radioimmunoassay } \\ \text { RP } & \text { Reversed-phase } \\ \text { HPLC-UV } & \begin{array}{l}\text { High-performance liquid } \\ \text { chromatography-Ultraviolet }\end{array} \\ \text { RSD } & \text { Relative standard deviation } \\ \text { RT } & \text { Retention time } \\ \text { SDS } & \text { Sodium dodecyl sulphate } \\ \text { SH } & \text { Skin homogenate } \\ \text { S/N } & \text { Signal-to-noise } \\ \text { SPE } & \text { Solid phase extraction }\end{array}$

\section{Introduction}

Providing women and adolescent girls with access to contraceptives and family planning services allows them to make their own decisions on whether they want to have children, when they want to have children and how many children they have [1]. Levonorgestrel (LNG), or D-Norgestrel, is a synthetic progestin commonly used for female contraception. LNG inhibits gonadotropin-releasing hormone release from 
the hypothalamus by activating progesterone and androgen receptors, resulting in inhibition of ovulation. It also increases the thickness of cervical mucus which obstructs the penetrability and survival of sperm [2]. LNG is the active pharmaceutical ingredient in contraceptive products that include emergency contraceptive pills [3], progestogenonly contraceptive pills [4], hormonal intrauterine devices [5] and subcutaneous implants [6]. Long-acting reversible contraceptives (LARCs) offer improved convenience and compliance and, through controlled daily release of the therapeutically-active dose, can minimise undesirable side effects $[6,7]$. However, commercially available long-acting injections and subcutaneous implants require painful invasive administration, typically by trained healthcare professionals, generate biohazardous sharps waste and, in the case of implants, require removal within a clinical setting [7].

Microneedle (MN) technology [8-12] provides a potential platform for development of a minimally invasive alternative method of long-acting contraception [13, 14]. MNs are micron-sized projections designed to puncture the outermost layer of skin, the stratum corneum, to facilitate local delivery of the therapeutic cargo into the cutaneous space whilst minimising pain and bleeding [15]. Recent studies in female Sprague Dawley rats have evaluated systemic uptake of LNG [16-19] or etonogestrel [20] following intradermal delivery of these progestin-only contraceptives from biodegradable MN systems. Enzyme-linked immunosorbent assay (ELISA) [17, 18] or HPLC/UPLC-MS [16, 19, 20] was used to analyse LNG levels in plasma; however whilst these in vivo studies in small mammals provide valuable data on systemic uptake of MN administered progestins, they do not fully characterise the local behaviour of the implant, i.e. drug release in the skin, and the results are caveated by acknowledged differences in the architecture and biology of human and rodent skin [21, 22]. In vivo studies are also time-consuming, expensive and subject to ethical scrutiny, and therefore, in vitro models and methods to better understand sustained intradermal progestin delivery are highly desirable.

The most prevalent apparatus used for in vitro laboratory characterisation of cutaneous dosage forms is static (Franz-type) and flow-through (Bronaugh-type) diffusion cells [23]. However, these tools are principally designed to characterise permeation of active pharmaceutical ingredients across a rate-limiting membrane that is designed to imitate the skin barrier. For a dosage form that negates the biological skin barrier, i.e. an intradermal implant, the critical attribute that needs to be characterised is drug release within the skin environment. In vitro dissolution tests for transdermal drug delivery systems [24] have therefore been adopted and adapted to characterise drug release from biodegradable MN devices [17-20, 25]. However, whilst these studies help characterise the dosage form, their biological relevance and correlation to the in vivo performance of an intradermal implant is unknown. Additional pre-clinical models and methods are therefore required to rapidly evaluate the delivery and, in the case of long-acting methods, the release characteristics of MN administered contraceptives in the dermal space.

Laboratory models must also be accompanied by a robust but sensitive validated analytical method that can detect and quantify candidate drugs, such as LNG, at clinically relevant concentrations. A range of analytical techniques including radioimmunoassay (RIA) [26, 27], ELISA [17, 18, 28], gas chromatography with mass spectrometry (GC-MS) [29, 30], liquid chromatography with mass spectrometry (LC-MS) [31-35] and high performance liquid chromatography (HPLC) accompanied by either ultraviolet (UV) [36, 37] or photo-diode array $[38,39]$ detection have been successfully used to quantify LNG in human plasma [27, 29, 32, $33,35]$, human serum [31, 34], breast milk [26, 30], human and primates' urine [28], rat plasma $[17,18,36]$ and in vitro media [37-39]. Many of these methodologies also rely upon an extraction step, typically performed using liquid-liquid extraction (LLE) [32, 33, 35]; however, the use of protein precipitation (PPT) $[33,34,40]$ and solid phase extraction (SPE) [41] has also been explored. However, there are no published studies describing the extraction and quantification of LNG in skin or skin models.

The aim of this study is to develop accessible, rapid, sensitive and reliable laboratory methods that can accurately determine intradermal release from sustained-release LNG dosage forms, using an in vitro release (IVR) medium and an ex vivo human skin homogenate ( $\mathrm{SH}$ ) medium accompanied by validated optimised extraction and analytical methods. Whilst this research has wide applicability to those developing intra- or trans-dermal contraceptive delivery systems, it is of particular relevance to current international efforts to develop MN-mediated progestin-based LARCs $[13,14]$.

\section{Materials and methods}

\section{Materials}

Lyophilised LNG (pharmaceutical grade of European Pharmacopeia reference; 99.9\% pure; MW: $312.45 \mathrm{~g} / \mathrm{mol}$ ), sodium phosphate monobasic and sodium phosphate dibasic were obtained from Sigma-Aldrich, UK. Jadelle ${ }^{\circledR}$ subcutaneous implants (Bayer, Germany) were a kind gift from the Population Council, New York, USA. LC-MS-grade water and acetonitrile, and hexane, isoamyl alcohol, ethyl acetate, diethyl ether, tert-butyl methyl ether and chloroform were purchased from Fisher Scientific, UK, and used as received. Sodium dodecyl sulphate (SDS) was purchased from VWR, UK. Phosphate-buffered saline (PBS) pH 7.2 was from 
Gibco (Thermo Fisher, UK). De-ionised water was obtained from a Purite water purification system, USA. All other solvents and chemicals were of analytical grade and stored at room temperature. A Techne sample concentrator supplied with a stream of gas nitrogen was used for the evaporation of organic solvents in a dry bath (Labnet digital, USA). The UV-Vis spectrophotometer was a Cary 60 (Agilent Technologies UK Ltd). Microcentrifuge tubes were vortex-mixed using an infrared vortex mixer (F202A0175FI, Fisherbrand, UK) and centrifuged using a microcentrifuge (Heraeus Fresco 17, Thermo Scientific, UK).

\section{HPLC-UV instrument}

Reversed-phase (RP) HPLC-UV analysis was performed using an UltiMate-3000 system (Thermo-Fisher, UK). The system is composed of an UltiMate LPG-3400SD standard quaternary pump, an UltiMate WPS-3000SL/TSL standard well plate autosampler, an UltiMate 3000 TCC-3000SD standard thermostatted column compartment and an UltiMate 3000 VWD variable wavelength detector. Chromatographic separation was performed using a C18 Kinetex ${ }^{\circledR}$ RP-HPLC column $(4.6 \times 250 \mathrm{~mm}$, particle size $5 \mu \mathrm{m}$, $100 \AA$ A), Phenomenex, USA. The column was protected by a SecurityGuard ultra cartridge (4.6 mm i.d.), Phenomenex, USA. Instrumental control of the HPLC system as well as data collection, processing and integration used Chromeleon 7.2 SR4 software (Thermo-Fisher, UK).

\section{Human breast skin explants}

Skin explants were collected following breast reduction surgery or mastectomy at the Royal Gwent Hospital, Newport, UK. The explants were obtained under informed written patient consent and local ethical committee approval (LREC Ref: 08/WSE03/55). Excised skin was transported to the laboratory in Dulbecco's modified Eagle's medium (DMEM) supplemented with $2 \%$ penicillin and streptomycin $(10,000 \mathrm{IU} / \mathrm{mL})$ and then used immediately, or frozen $\left(-20^{\circ} \mathrm{C}\right)$ and used at a subsequent time, as previously described [42].

\section{Development of a HPLC-UV method to quantify LNG}

\section{Preparation of LNG calibration standards for HPLC-UV}

LNG powder was transferred to a $2 \mathrm{~mL}$ microcentrifuge tube and its mass indirectly determined using a micro-balance (Sartorius MC 5, Germany). A standard LNG stock solution $(360 \mu \mathrm{g} / \mathrm{mL})$ was prepared using LC-MS grade acetonitrile (ACN). LNG calibration standards: $25,15,5,1,0.5,0.25$, $0.05,0.01,0.005,0.0025$ and $0.001 \mu \mathrm{g} / \mathrm{mL}$ were then prepared by serial dilution with LC-MS ACN to create two calibration curves, 0.005 to $0.5 \mu \mathrm{g} / \mathrm{mL}$ and 0.5 to $25 \mu \mathrm{g} / \mathrm{mL}$. LNG calibration standards were also used to 'spike' the IVR $(0.4,1.6,3.6$ and $19.0 \mu \mathrm{g} / \mathrm{mL})$ and $\mathrm{SH}(3.6$ and $19.0 \mu \mathrm{g} / \mathrm{mL})$ media to evaluate method specificity. Standard LNG stock solutions, as well as calibration standards (stored in $2 \mathrm{~mL}$ glass HPLC vials), were stored at $-20^{\circ} \mathrm{C}$. All samples were equilibrated in the HPLC sampler at $4{ }^{\circ} \mathrm{C}$ for 15 min prior to use.

\section{HPLC-UV method development and optimisation}

Initial HPLC-UV analyses were performed using $20 \mu \mathrm{L}$ of the LNG calibration standard, $15 \mu \mathrm{g} / \mathrm{mL}$, and an isocratic mobile phase containing LC-MS grade ACN/water (ACN: $\left.\mathrm{H}_{2} \mathrm{O}\right)$ 80:20 (v/v) with a flow rate of $1 \mathrm{~mL} / \mathrm{min}$ for a total run time of $12 \mathrm{~min}$. The column temperature was set at $25^{\circ} \mathrm{C}$, and the UV absorbance was recorded at $236 \mathrm{~nm}$. The method was then optimised by independent modification of (i) mobile phase composition, (ii) flow rate, (iii) the wavelength for UV detection and (iv) column temperature. Isocratic and gradient elution methods were examined, and several mobile phase ratios $\left(\mathrm{ACN}: \mathrm{H}_{2} \mathrm{O}\right)$ were tested between 50:50 and 100:00 (v/v). The wavelength for detection was optimised within the UV range of 225 to $248 \mathrm{~nm}$. The flow rates examined included 0.5 , $0.75,1$ and $1.25 \mathrm{~mL} / \mathrm{min}$. Column temperatures between 25 and $50{ }^{\circ} \mathrm{C}$ were also evaluated within this optimisation process.

\section{Optimised HPLC-UV method}

The optimal chromatographic conditions for LNG detection consisted of a gradient elution of $\mathrm{ACN}: \mathrm{H}_{2} \mathrm{O}$, at a flow rate of $1 \mathrm{~mL} / \mathrm{min}$, starting at $60: 40(\mathrm{v} / \mathrm{v})$, changing to 100:00 (v/v) at $4.4 \mathrm{~min}$ and then returning to $60: 40(\mathrm{v} / \mathrm{v})$ at $5 \mathrm{~min}$. The injected sample volume was $20 \mu \mathrm{L}$, and LNG absorbance was recorded at $244 \mathrm{~nm}$. The column temperature was set at $37{ }^{\circ} \mathrm{C}$, and a single run lasted $7.5 \mathrm{~min}$. Negative controls for HPLC-UV analyses included LC-MS grade ACN and IVR medium.

\section{Validation of the optimised HPLC-UV method for LNG}

The optimised HPLC-UV method was validated using LNG calibration standards according to recommendations of the International Council for Harmonisation (ICH) [43] and European Pharmacopeia [44]. The method was validated in terms of specificity, linearity, sensitivity, precision and accuracy. 


\section{Specificity}

The assay was developed to quantify LNG in both IVR and SH media (see "Preparation of in vitro release medium and ex vivo human skin homogenate medium to analyse LNG release"). The HPLC-UV chromatograms of (i) negative controls of ACN, IVR medium and SH medium; (ii) LNG calibration standards $(7.5$ and $15 \mu \mathrm{g} / \mathrm{mL})$ in ACN and (iii) spiked LNG preparations in IVR medium or $\mathrm{SH}$ medium were recorded using the optimised HPLC-UV method ("Optimised HPLC-UV method"). Specificity was evaluated by visual inspection of the recorded chromatograms and quantitative comparison of the area under the curves (AUCs) and retention times (RT) of the LNG peaks. Samples containing LNG in ACN or IVR medium were analysed directly, while LNG in SH medium was subjected to an extraction step ("LLE of LNG from human skin homogenate medium") prior to HPLC-UV analysis.

\section{Linearity}

Nine LNG calibration standards were prepared in triplicate, assayed using the optimised HPLC-UV method and analysed (by calculating AUCs) to construct two calibration curves, with each curve containing 5 concentrations $(0.005$ to $0.5 \mu \mathrm{g} / \mathrm{mL}$ and 0.5 to $25 \mu \mathrm{g} / \mathrm{mL})$. The 'least squares' method was used to assess linearity.

\section{Sensitivity}

Method sensitivity was evaluated by determining the limits of detection (LOD) and quantification (LOQ). LOD and LOQ were estimated using the 'signal-to-noise $(\mathrm{S} / \mathrm{N})$ ' method specified in the European Pharmacopeia [44]. The peak-to-peak noise in proximity to the LNG peak was measured, and LOD and LOQ were estimated to be 3 and 10 times greater than the $\mathrm{S} / \mathrm{N}$ value, respectively, according to the formula: $\mathrm{S} / \mathrm{N}=2 \mathrm{H} / \mathrm{h}$, where $H$ is the height of LNG peak and $h$ is the maximum peak-to-peak noise within a time period equating to 20 times the peak width at half-height. Three independent experiments $(n=3)$ were used to calculate mean LOD and LOQ values.

\section{Precision}

Intra-day (repeatability) and inter-day (intermediate) precisions were evaluated by analysing LNG calibration standards ("Linearity") (i) on the same day ( $n=3)$ and (ii) over three consecutive days $(n=3)$ respectively. Relative standard deviations (\%RSD) and relative errors (\%RE), expressed as a percentage, were calculated.

\section{Accuracy}

Method accuracy was evaluated in accordance with the 'standard additions' method whereby a known volume of LNG calibration standard $(0.5,1$ and $5 \mu \mathrm{g} / \mathrm{mL})$ was added to a previously defined sample $(1 \mu \mathrm{g} / \mathrm{mL})$, to achieve either $25 \%, 50 \%, 100 \%$ or $200 \%$ additions to the concentration. ICH guidance for accuracy validation recommends conducting a minimum of nine determinations over a minimum of 3 concentrations of the analyte [43]. The accuracy was then calculated by comparing the theoretical added mass of LNG to the measured value. Measurements were performed in triplicate and the \%RSD and \%RE were calculated.

\section{Preparation of in vitro release medium and ex vivo human skin homogenate medium to analyse LNG release}

IVR medium consists of $100 \mathrm{mM}$ phosphate buffer supplemented with $0.5 \%$ sodium dodecyl sulphate (SDS) and is adjusted to $\mathrm{pH} 7.4$ using $1 \mathrm{M}$ sodium hydroxide.

To prepare SH medium, frozen excised human breast skin explants ("Human breast skin explants") were first defrosted and subcutaneous fat removed by blunt dissection. The skin was then rinsed in PBS $1 \times(10 \mathrm{mM}, \mathrm{pH} 7.2)$, secured on foil-covered dissection corkboards (epidermis side up) and surface wiped with $70 \% \mathrm{v} / \mathrm{v}$ ethanol prior to removal of biopsies ( $8 \mathrm{~mm}$ diameter) using a biopsy punch (Miltex, Japan). Biopsies were immersed in PBS $(1 \times)$ before transfer to a glass tube containing $2 \mathrm{~mL}$ of IVR medium. Biopsy homogenisation was achieved using a vertical bar homogeniser (Polytron PT 1600E, Kinematica, Switzerland) at progressively increasing speeds (1000-30,000 rpm) until a visibly uniform suspension was obtained. Homogenates of several skin biopsies, from the same donor, were pooled, and $2 \mathrm{~mL}$ of this pooled homogenate was then further diluted with IVR medium to a final volume of $7.5 \mathrm{~mL}$. The resulting medium is termed SH medium.

\section{Development of a liquid-liquid extraction (LLE) procedure to isolate LNG from human skin homogenate medium}

\section{LLE of LNG from human skin homogenate medium}

The extraction procedure was developed in three stages. In Stage 1 (Solvent selection), LNG was spiked into both water and IVR medium, and a range of organic solvents (Table 1), identified from previous published (Table 1) and unpublished work, were evaluated for their ability to recover the spiked LNG. In this preliminary stage, the extraction process (described in detail in Fig. 1) used a single extraction step (i.e. re-extraction identified as step d in Fig. 1 was omitted) due to 
Table 1 Initial LLE (liquid-liquid extraction) procedures were conducted using a range of solvents. A list of the organic phases that were evaluated and the reference source used to identify them are presented in this table

\begin{tabular}{lll}
\hline Organic solvents & Ratio & Reference \\
\hline Hexane: iso-amyl alcohol & $90: 10$ & {$[36]$} \\
Hexane: iso-amyl alcohol & $98: 02$ & {$[32]$} \\
Hexane/ethyl acetate & $70: 30$ & {$[40]$} \\
Di-ethyl ether & 100 & {$[26,31]$} \\
Tert-butyl methyl ether & 100 & {$[35]$} \\
Ethyl acetate & 100 & {$[33]$} \\
Chloroform/methanol & $2: 1$ & - \\
Hexane & 100 & - \\
Iso-amyl alcohol & 100 & - \\
\hline
\end{tabular}

the simplicity of the aqueous medium. To perform the extraction, $1 \mathrm{~mL}$ of the organic solvent was added to $1 \mathrm{~mL}$ of the $\mathrm{LNG}$ spiked media, and extractions were performed in triplicate. The process was repeated using both water and IVR medium and using two different concentrations of LNG, nominally referred to as 'high' $(1.6 \mu \mathrm{g} / \mathrm{mL})$ and 'low' concentrations $(0.4 \mu \mathrm{g} / \mathrm{mL})$.

Selection of the most appropriate organic phase for extraction (Stage 1) was followed by a two-step LNG extraction procedure (Fig. 1) to try and increase the extraction efficiency from the more complex biological $\mathrm{SH}$ medium. Stage 2 (Two-step extraction) was evaluated using both IVR medium and SH medium ( $n=3$ each), each spiked with LNG to produce $950 \mu \mathrm{L}$ medium containing $19.0 \mu \mathrm{g} /$ $\mathrm{mL}$ LNG. The extractions used $500 \mu \mathrm{L}$ of ethyl acetate in the first extraction step and $150 \mu \mathrm{L}$ of ethyl acetate in the re-extraction step.

Stage 3 (Optimisation and validation) involved minor refinements to the protocol and examined the reproducibility of the extraction process in SH medium over 3 consecutive days (performed in triplicate on each day). In this final stage, SH samples $(n=9)$ were spiked with LNG to produce a $1 \mathrm{~mL}$ spiked medium containing $3.6 \mu \mathrm{g} / \mathrm{mL}$ LNG. The optimised two-step extraction procedure, illustrated for the SH medium in Fig. 1, was then used to recover the LNG. Briefly, $550 \mu \mathrm{L}$ of ethyl acetate was added to $500 \mu \mathrm{L}$ of SH sample in a $2 \mathrm{~mL}$ microcentrifuge tube. After equilibration at room temperature for at least $15 \mathrm{~min}$, the mixture was vortexed at $2400 \mathrm{rpm}$ for $3 \mathrm{~min}$ and then centrifuged for $5 \mathrm{~min}$ at $4000 \mathrm{rpm}$, (step a). The aqueous phase was then frozen at $-20^{\circ} \mathrm{C}$, to separate the organic and aqueous layers (step b), and the organic supernatant was manually extracted using a pipette (step c). The thawed aqueous residue was

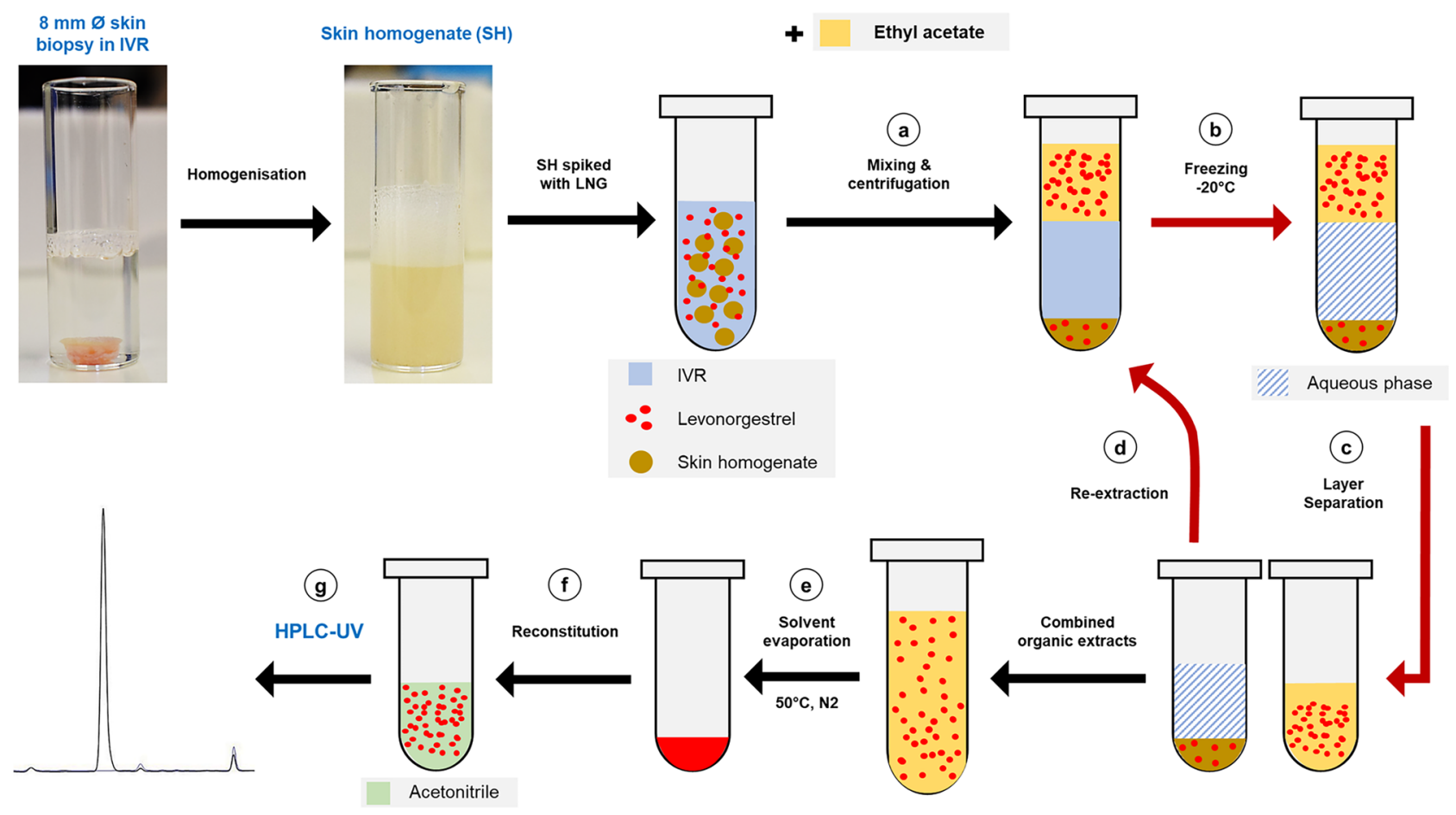

Fig. 1 Schematic illustration of the validated LLE (liquid-liquid extraction) procedure for LNG extraction from $\mathrm{SH}$ medium. $\mathrm{SH}$ medium was prepared by homogenising an $8 \mathrm{~mm}$ diameter skin biopsy in IVR medium using a vertical bar homogeniser. The SH medium was then spiked with an LNG calibration standard and extracted with ethyl acetate as follows: the mixture was vigorously vortex-mixed and then centrifuged (a). The mixture was then stored at $-20{ }^{\circ} \mathrm{C}$ (b) allowing the aqueous phase to freeze and enabling the organic supernatant to be collected (c). The aqueous layer was then thawed and re-extracted (d), and the combined organic extracts were evaporated to dryness (e). Finally, the residual powder was reconstituted in acetonitrile (f) and analysed by HPLC-UV (g) 
then re-extracted with $165 \mu \mathrm{L}$ of ethyl acetate following the same procedure (step d). The extracts were then combined and evaporated to dryness in a sample concentrator, under a stream of nitrogen gas at $50{ }^{\circ} \mathrm{C}$ (step e). The residual powder was then reconstituted in $200 \mu \mathrm{L}$ of $\mathrm{ACN}$, vortex-mixed for $1 \mathrm{~min}$ at $2400 \mathrm{rpm}$ (step f) and finally analysed using an optimised HPLC-UV method to quantify LNG (step g).

\section{Calculation of extraction recovery efficiency}

Two extraction controls (referred to as $E C 1$ and $E C 2$ ) were prepared by spiking ACN with known volumes of an LNG calibration standard. $E C l$ was a positive control that was not subjected to any of the extraction protocol ("LLE of LNG from human skin homogenate medium"). EC2 was a positive control subjected to the evaporation and reconstitution steps (Fig. 1, steps $\mathrm{e}-\mathrm{f}$ ) to determine if evaporation resulted in loss of the LNG analyte. Both ECs were analysed using the optimised HPLC-UV method. The extraction recovery efficiencies of LNG were calculated in comparison to $E C l$ according to the formula:

Extraction Recovery Efficiency\% $=\frac{C o n_{\text {sample }} \times V_{\text {sample }} \times D F_{\text {sample }}}{C o n_{\mathrm{EC} 1} \times V_{\mathrm{ECl}} \times D F_{\mathrm{EC} 1}} \times 100$

where:

$\mathrm{Con}_{\text {sample }}$ and $\mathrm{Con}_{\mathrm{EC} 1}(\mu \mathrm{g} / \mathrm{mL})$ are the measured LNG concentrations within the extracted sample and EC1 respectively.

$V_{\text {sample }}$ and $V_{\mathrm{EC} 1}(\mathrm{~mL})$ are the volumes of the extracted sample and EC1 control.

$D F_{\text {sample }}$ and $D F_{\mathrm{EC} 1}$ are the dilution factors of the extracted sample and EC1 before the HPLC-UV analysis.

\section{Evaluation of in vitro release medium and ex vivo human skin homogenate medium to characterise LNG release from a commercially available sustained release formulation}

A commercially available subcutaneous implant, Jadelle ${ }^{\circledR}$ (75 mg LNG per rod), was used to confirm the suitability of the models and method developed in this study. LNG release with time was characterised by placing a single Jadelle ${ }^{\circledR}$ rod in $15 \mathrm{~mL}$ of IVR medium or SH medium, in a shaking (200 rpm) water bath maintained at $37{ }^{\circ} \mathrm{C}$. At 7, 14 and 28 days, a $500 \mu \mathrm{L}$ sample was removed from the release medium (which was replenished with fresh medium) for analysis. IVR and SH samples were extracted with ethyl acetate according to the optimised protocol (Fig. 1), and LNG was quantified using the optimised HPLC-UV method ("Optimised HPLC-UV method"). A further sample was taken from the IVR medium and directly analysed, i.e. without being subjected to the extraction process, using the optimised HPLC-UV assay.

\section{Results and discussion}

Microneedles have emerged in recent years as a potential platform for sustained release of LNG, and other contraceptives, into the skin. This is an exciting, internationally recognised clinical application for microneedles, as exemplified by a recent review and a business case analysis commissioned by PATH $[13,14]$. There are however no standardised in vitro and ex vivo models or methods to examine sustained progestin release in the skin because there are no established methods of drug delivery that can target this body compartment. The emergence of microneedle-based progestin delivery systems therefore creates a need to develop validated laboratory tools. These tools must be skin specific (as skin is the target organ for microneedles) and highly sensitive (because LNG release from microneedles is likely to be in the low microgram range). This study introduces new biologically relevant in vitro/ex vivo drug release models, an optimised extraction procedure and a validated sensitive HPLC-UV methodology which, when used in combination, can accurately evaluate and understand LNG release kinetics in the dermis at $\mathrm{ng} / \mathrm{mL}$ concentrations.

\section{Developing supplemented media to evaluate LNG release in the skin}

The development of MN approaches that confer extended drug release challenges the boundaries of existing laboratory models. Whereas existing commercial LARC products deliver the progestin cargo into subcutaneous (implant) or intramuscular (injection) compartments, MN-based approaches deliver the drug into the skin. Whilst it would be preferable to monitor the drug release profile within intact excised skin, this is only possible over a few days, rather than several months. An initial evaluation of drug release and dissolution can however be performed using relatively simple apparatus and IVR media adapted (with respect to composition, $\mathrm{pH}$, volume, temperature) for the specific analyte and formulation. Several IVR media have been successfully used to characterise LNG or etonogestrel release from MNs and other delivery systems. Examples include standard PBS [25, 45] or PBS supplemented with a surfactant, such as $0.5 \%$ SDS [25] or polyethylene glycol 400 at 30\% [20] or $40 \%$ [19], to facilitate dissolution of the lipophilic analytes. Accelerated release conditions can also be created by addition of an organic solvent such as $25 \%$ ethanol $[45,46]$ or an organic solvent (e.g. ethanol, isopropanol, tert-butanol or tetrahydrofuran) with a surfactant (Tween-20, Tween-80 or SDS) [17, 18, 45, 47]. Whilst such studies allow for an abbreviated, yet informative, release study, the influence of the solvent conditions on the release mechanism and kinetics should be viewed with caution when interpreting the data. 
This study used a phosphate-buffered medium supplemented with $0.5 \%$ SDS to provide a simple, yet valuable, IVR model for comparing LNG release from different formulations at the early screening stage.

However, drug release within a simple aqueous environment may not be predictive of drug release within the skin. Previous studies have investigated the diffusion and stability of molecules within skin matrices. Ito et al. [48] evaluated the stability of leuprorelin acetate delivered to skin via MNs using a rat SH model [48]. Other groups have used SH of animal origin as surrogates for in vivo conditions to study the impact of exogenous fatty acids on bacterial membrane composition and function [49], to measure the concentrations of different metabolites [50-52] and to evaluate the accuracy of theranostic applications [53].

In this study, we developed and tested a representative ex vivo drug release model containing all of the biological components of human skin, i.e. IVR medium supplemented with human $\mathrm{SH}$, to provide a bridge between in vitro and in vivo drug release studies.

\section{Development, optimisation and validation of a sensitive HPLC-UV method to quantify LNG}

A reliable method to detect potent drug molecules released from an intradermally administered long-acting contraceptive will require high levels of sensitivity, specificity and repeatability. In this study, a HPLC-UV chromatographic methodology was iteratively developed (summarised in Supplementary Table 1) to optimise peak sharpness, AUC, retention time and separation. A simple LNG solution was initially analysed adapting a published method [36, 38], and this produced a sharp symmetrical LNG peak at a retention time of $3.65 \mathrm{~min}$, with neither a peak front, tail or interfering peaks compared to the negative control. However, quantification of LNG within a biologically representative medium, i.e. SH, necessitated a drug extraction step ("LLE of LNG from human skin homogenate medium") and optimisation of the HPLC-UV assay to eliminate the impact of potential interferent on LNG quantification.

Separation efficiency was enhanced by progressively reducing the proportion of $\mathrm{ACN}$ in the $\mathrm{ACN}: \mathrm{H}_{2} \mathrm{O}$ mobile phase from $100 \%$ to $50 \%$. This increased the retention time of the peak from 3.22 to $9.56 \mathrm{~min}(\mathrm{LNG} \log \mathrm{P}=3.8$ ), a strategy that was also used by Zaidi et al. [37] for LNG quantification. However, an increased retention time was associated with a concomitant reduction in peak sharpness, an undesirable characteristic that reduces the sensitivity. A gradient elution mode was therefore employed, initiated at a mobile phase ratio of $60: 40 \% \mathrm{v} / \mathrm{v}\left(\mathrm{ACN}: \mathrm{H}_{2} \mathrm{O}\right)$ and changed to either $90: 10,95: 05$ or $100: 00 \% \mathrm{v} / \mathrm{v}$ at $4.4 \mathrm{~min}$ to facilitate more rapid elution of LNG through the column, before returning to $60: 40 \% \mathrm{v} / \mathrm{v}$. Each of the ratios tested in this gradient elution method provided sharp symmetrical peaks. However, the key factor was to ensure that the LNG peak was distinct from potential interferent in the extracted $\mathrm{SH}$ (negative controls) (Fig. 2a). An $\mathrm{ACN}: \mathrm{H}_{2} \mathrm{O}$ ratio of 100:00 (v/v) at $4.4 \mathrm{~min}$ to 5 min was therefore selected as the preferred mobile phase as it produced an LNG retention time $(\sim 4.8 \mathrm{~min})$ that was chronologically distinct from significant interferent peaks (Fig. 2b). Whilst gradient elution is not commonly used in the published literature to detect LNG, Wang et al. [41] and Cirrincione et al. [35] used this approach to detect LNG within human plasma samples following administration via oral [41] and subdermal implants [35]. The data reported in this study therefore indicates that gradient elution can also facilitate HPLC-UV analysis of LNG extracted from human skin.

Optimisation of the mobile phase composition was accompanied by refinement of method parameters (detailed in Supplementary Table 1) to further increase sensitivity, including the flow rate $(1.0 \mathrm{~mL} / \mathrm{min})$ [54], the wavelength for UV absorbance of LNG (244 nm) and the column temperature $\left(37^{\circ} \mathrm{C}\right)$. Using these optimised conditions, the tailing factor of the LNG peak was $<2$ in ACN, IVR and extracted $\mathrm{SH}$, which fulfils the recommendations of the FDA for peak symmetry [55]. The principal characteristics of this optimised HPLC-UV assay were then evaluated in turn, as described in "Specificity," "Linearity and sensitivity," "Precision," to "Accuracy."

\section{Specificity}

Sharp symmetrical LNG peaks were recorded at $\sim 4.8 \mathrm{~min}$ in ACN and IVR (Supplementary Fig. 1) at a range of LNG concentrations 0.005 to $25 \mu \mathrm{g} / \mathrm{mL}$. The retention time and peak shape are comparable to those observed in the $\mathrm{SH}$ extract (Fig. 2b) and thus demonstrate that major cutaneous interferent, which are eluted both before and after the LNG peak, do not have a significant impact on the specificity of the method. A similar approach was previously reported by Liu et al. [33].

\section{Linearity and sensitivity}

Assay linearity was established over a wide range of concentrations, with two calibration curves $(0.005$ to $0.5 \mu \mathrm{g} / \mathrm{mL}$ and 0.5 to $25 \mu \mathrm{g} / \mathrm{mL}$ ) producing correlation coefficients equal to 1 (Supplementary Fig. 2). The LOD and LOQ for LNG using the optimised HPLC-UV method was $0.001 \mu \mathrm{g} / \mathrm{mL}$ and $0.005 \mu \mathrm{g} /$ $\mathrm{mL}$ respectively (Supplementary Table 2), which is a significant improvement on values that are typically reported in the published literature for HPLC-UV methods, e.g. $2.79 \mu \mathrm{g} / \mathrm{mL}$ [39] and $10 \mu \mathrm{g} / \mathrm{mL}$ [56], and is equivalent to the LOQ (5 ng/ $\mathrm{mL}$ ) [31] achieved using LC-Tandem MS to quantify LNG extracted from human serum samples. Whilst lower LOQ 


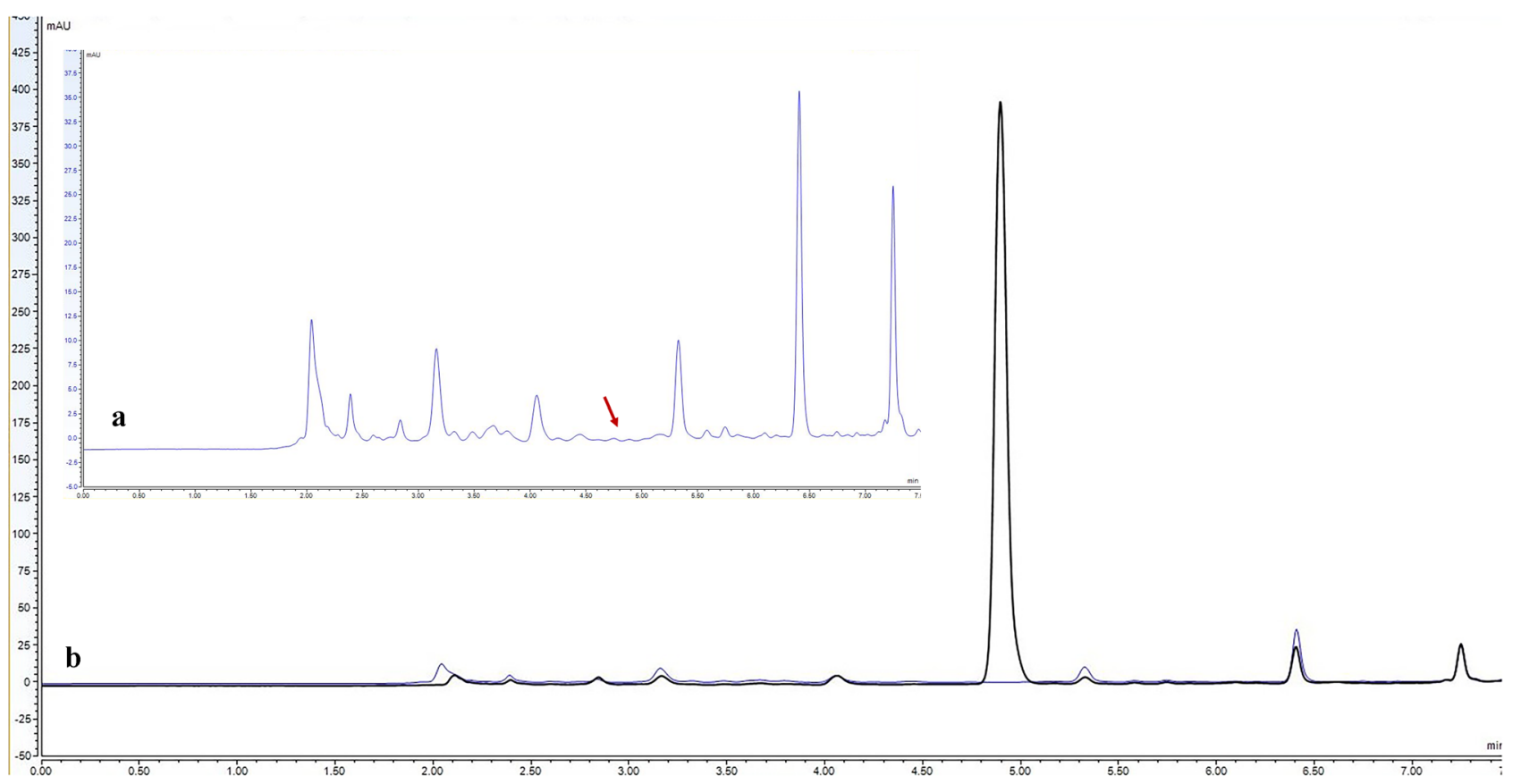

Fig. 2 Illustrative overlaid HPLC-UV chromatograms of (a) the extract of SH medium and (b) the extract of LNG spiked in $\mathrm{SH}$ medium. (a) Magnified HPLC-UV chromatogram of extracted SH medium (negative control), with the red arrow indicating the absence of interfering peaks at the optimized LNG retention time. (b) Representative HPLC-UV chromatogram of extracted LNG (black) from spiked SH medium $(1.6 \mu \mathrm{g} / \mathrm{ml})$ compared to the $\mathrm{SH}$ extract alone, i.e. the negative control (grey). A sharp, symmetrical peak at $\sim 4.8 \mathrm{~min}$ is LNG. Both SH extracts were prepared while developing the two-step extraction procedure and analysed using the optimised HPLC-UV method ("Optimised HPLC-UV method"). X axis: time ( $\mathrm{min}), \mathrm{Y}$ axis: UV absorbance (mAU)

\section{Precision}

The intra- and inter-day precisions of the HPLC-UV method were evaluated by determining the relative standard deviation (\%RSD) and relative error (\%RE) of nine calibration standard concentrations $(n=3)$ over three consecutive days (Table 2). Intra-day precision of the method produced \%RSD values between $0.26 \%$ and $1.4 \%$, while for the inter-day precision, \%RSD values ranged from 0.08 to $4.16 \%$ (Table 2 ).

Data is presented as a mean concentration \pm standard deviation (SD), the percentage RSD (relative standard deviation) and percentage RE (relative error)
Table 2 Intra- and inter-day precisions of the HPLC-UV method.
Each LNG calibration standard was analysed three times on the day (intra-day precision), or once over 3 days, (inter-day precision).

\begin{tabular}{|c|c|c|c|c|c|c|}
\hline \multirow{2}{*}{$\begin{array}{l}\text { Theoretical concentration } \\
(\mu \mathrm{g} / \mathrm{mL})\end{array}$} & \multicolumn{3}{|l|}{ Intra-day precision } & \multicolumn{3}{|l|}{ Inter-day precision } \\
\hline & $\begin{array}{l}\text { Measured concentration } \pm \mathrm{SD} \\
(\mu \mathrm{g} / \mathrm{mL})\end{array}$ & $\pm \mathrm{RSD}(\%)$ & $\pm \mathrm{RE}(\%)$ & $\begin{array}{l}\text { Measured concentration } \pm \text { SD } \\
(\mu \mathrm{g} / \mathrm{mL})\end{array}$ & $\pm \operatorname{RSD}(\%)$ & $\pm \mathrm{RE}(\%)$ \\
\hline 0.005 & $0.0053 \pm 0.000018$ & 0.34 & 7.85 & $0.0053 \pm 0.0002$ & 4.16 & 6.37 \\
\hline 0.01 & $0.01 \pm 0.0001$ & 1.09 & 0.67 & $0.01 \pm 0.00008$ & 0.8 & 0.46 \\
\hline 0.05 & $0.0497 \pm 0.0006$ & 1.4 & 0.4 & $0.0497 \pm 0.0002$ & 0.53 & 0.42 \\
\hline 0.25 & $0.25 \pm 0.002$ & 1.11 & 0.18 & $0.249 \pm 0.0009$ & 0.36 & 0.2 \\
\hline 0.5 & $0.503 \pm 0.005$ & 1.12 & 0.77 & $0.503 \pm 0.0008$ & 0.16 & 0.67 \\
\hline 1 & $1.0003 \pm 0.005$ & 0.56 & 0.03 & $0.99 \pm 0.0007$ & 0.08 & 0.08 \\
\hline 5 & $5.009 \pm 0.013$ & 0.26 & 0.2 & $5.004 \pm 0.008$ & 0.16 & 0.084 \\
\hline 15 & $14.99 \pm 0.06$ & 0.42 & 0.06 & $14.98 \pm 0.02$ & 0.13 & 0.13 \\
\hline 25 & $25.04 \pm 0.09$ & 0.35 & 0.16 & $24.99 \pm 0.07$ & 0.27 & 0.005 \\
\hline
\end{tabular}


Table 3 HPLC-UV method accuracy using the standard additions method. A known volume of an LNG standard solution was added to $100 \mathrm{ng}$ of $\mathrm{LNG}(100 \mu \mathrm{L}$ of the $1 \mu \mathrm{g} / \mathrm{mL}$ calibration standard) to achieve a 25, 50, 100 or $200 \%$ increase in the LNG mass on column. The measured masses were then compared to the theoretical values to determine the accuracy by $\% \mathrm{RSD}$ and $\% \mathrm{RE}$

\begin{tabular}{llrll}
\hline $\begin{array}{l}\text { LNG mass } \\
\text { added (\%) }\end{array}$ & $\begin{array}{l}\text { Total theoretical } \\
\text { mass (ng) }\end{array}$ & $\begin{array}{l}\text { Measured } \\
\text { mass } \pm \text { SD } \\
(\mathbf{n g})\end{array}$ & RSD (\%) & RE (\%) \\
\hline 25 & 125 & $128.5 \pm 3.53$ & 2.75 & 2.79 \\
50 & 150 & $154.16 \pm 1.51$ & 0.97 & 2.77 \\
100 & 200 & $204.47 \pm 0.93$ & 0.45 & 2.23 \\
200 & 300 & $314 \pm 4.86$ & 1.54 & 4.87 \\
\hline
\end{tabular}

As might be expected, relative errors were greatest as values approached the LOQ $(0.005 \mu \mathrm{g} / \mathrm{mL})$.

\section{Accuracy}

Method accuracy or trueness describes the closeness of observed quantities to their theoretical values and was evaluated using the 'standard additions' method. The selected additions of LNG used in this study were $25 \%, 50 \%, 100 \%$ and $200 \%$, and the accuracies (based on measured mass compared to theoretical values) were $102.8 \%, 102.8 \%$,
$102.2 \%$ and $104.9 \%$ respectively, with relative errors of less than $5 \%$ (Table 3 ).

\section{Development of an LLE procedure to isolate LNG from human skin homogenate medium}

The use of SH medium for drug release studies will require a drug extraction and recovery method that separates the released analyte from the diverse biological interferent. In this study, a novel two-step liquid-liquid extraction (LLE) procedure for the efficient recovery of LNG from a dermal matrix is reported. The LLE procedure was developed in three stages. In Stage 1, several organic solvents were examined as means to extract LNG from a simple aqueous solution spiked with a 'high' $(1.6 \mu \mathrm{g} / \mathrm{mL}) \mathrm{LNG}$ concentration. The extraction recoveries ranged between $32.5 \pm 9.5 \%(n=6)$ for hexane and $91 \pm 3.5 \%(n=6)$ for ethyl acetate, which was the best performing organic solvent. Similar results were observed with the IVR samples spiked with high $(1.6 \mu \mathrm{g} / \mathrm{mL})$ and 'low' $(0.4 \mu \mathrm{g} / \mathrm{mL}) \mathrm{LNG}$ concentrations where ethyl acetate achieved the highest recovery efficiencies, $77.94 \pm 10.03 \%$ ( $n$ $=3$ ) and $75.3 \pm 3.38 \%(n=2)$, respectively. Figure 3 summarises the extraction recovery efficiencies achieved using multiple organic phases in comparison to the positive extraction control, EC1.

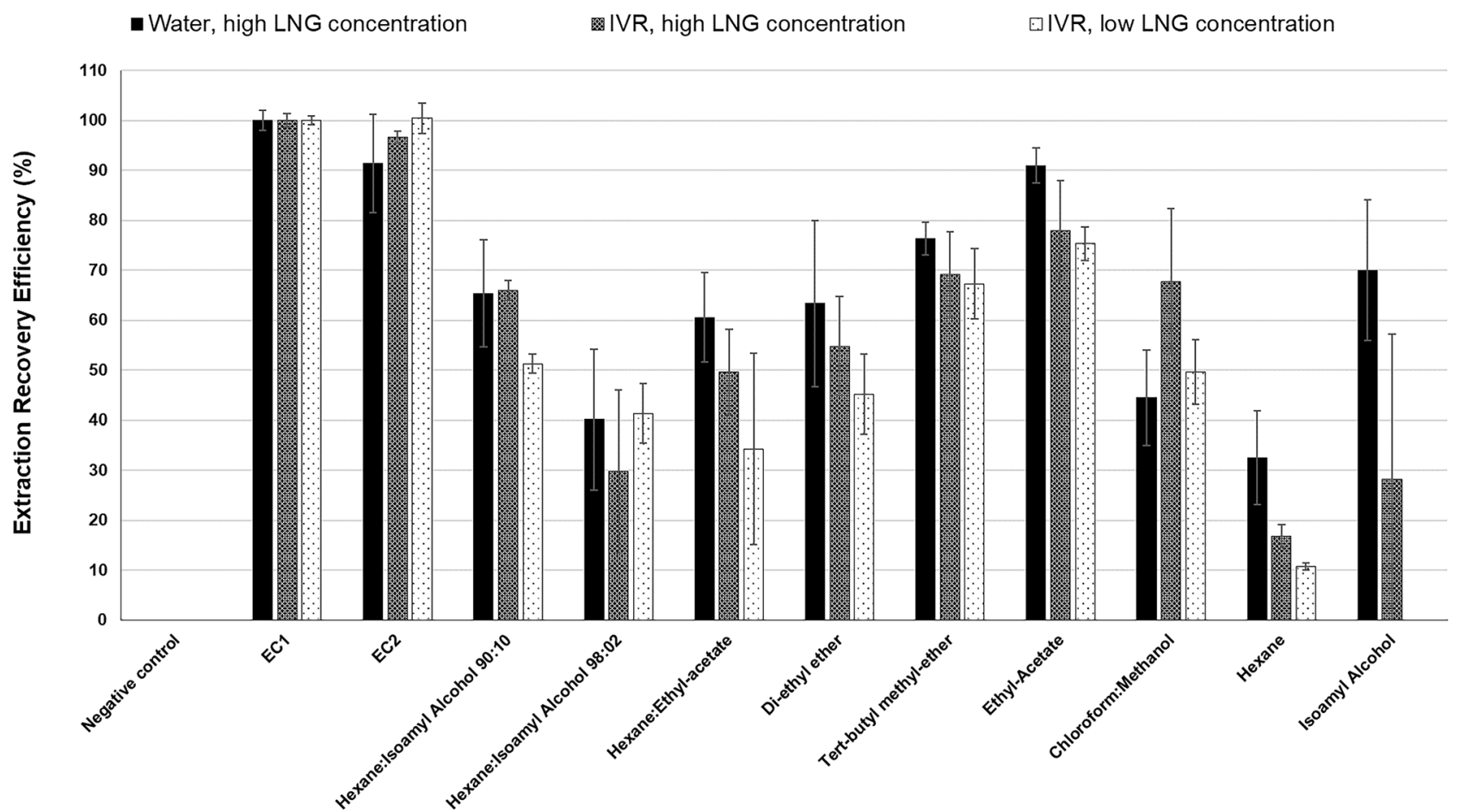

Fig. 3 The extraction recovery efficiencies of different organic solvents from two simple media (water and IVR medium) using a 'high' $(1.6 \mu \mathrm{g} / \mathrm{mL})$ or 'low' $(0.4 \mu \mathrm{g} / \mathrm{mL})$ spiked LNG concentration. Extraction recovery efficiencies were calculated in comparison to an untreated extraction control (EC1) which was not subject to any of the extraction steps. Data shown are the means \pm SD. For water samples; $n=6$. For IVR samples at high concentration; $n=3$ except for tert-butyl methyl-ether and isoamyl alcohol where $n=2$, while at low concentration; $n=2$ each except for isoamyl alcohol where $n=0$ 
After selecting ethyl acetate as the preferred extraction solvent, a two-step extraction procedure was evaluated (Stage 2) to optimise LNG recovery from the more complex biological SH medium whilst also reducing the volumes of organic solvent used in the process (35\% reduction). In this two-step procedure, LNG recovery increased between the 1 st and 2nd extractions, achieving a combined recovery efficiency of $92.5 \pm 2 \%$ in IVR $(n=3)$ and $88.5 \pm 1 \%$ in SH $(n=3)$ (Fig. 4a). The two-step extraction method was further validated over 3 consecutive days (Stage-3) to provide mean intra- and inter-day recovery efficiencies (Fig. 4b; Supplementary Table 3). The final extraction efficiency of LNG from SH medium using the optimised two-step extraction procedure and increased experimental replicates was $84.61 \pm 1.64 \%(n=9)$.

LNG has previously been isolated and quantified from various biological samples using similar LLE protocols: the volume of extracted sample, number of extraction cycles and organic solvent being the main variables. Sample volume depends on the nature of the sample, e.g. $5 \mathrm{~mL}$ for breastfeeding milk samples [26] and between $100 \mu \mathrm{L}$ and $1 \mathrm{~mL}[31-33,36,40]$ for plasma and serum samples. The current study used $500 \mu \mathrm{L}$ of SH medium for LLE. Whilst extractions from plasma/serum samples have generally adopted one-step LLE, the employment
Fig. 5 Illustrative overlaid HPLC-UV chromatograms of LNG released from Jadelle ${ }^{\circledR}$ implants in IVR $(\mathbf{a}, \mathbf{b})$ and SH (c) media. Samples of IVR $(n=1)$ and SH media $(n=1)$ were collected at days 7 (black), 14 (blue) and 28 (brown). LNG in IVR samples (a) was directly assayed by HPLC using the optimised method ("Optimised HPLC-UV method"). Further IVR samples (b) were subjected to an extraction step to illustrate the efficiency of the extraction procedure. In SH samples, (c) LNG was also recovered using the optimised extraction procedure ("LLE of LNG from human skin homogenate medium") prior to analysis

of a two-step protocol was reported for breastfeeding milk samples, which was complemented with RIA to yield an $82 \%$ extraction recovery efficiency [26]. The second extraction step used in this study enhanced the total extraction efficiency of LNG from SH medium by a further $3.4 \pm 1.75 \%(n=9)$. Although further extraction cycles could incrementally improve LNG recovery, this must be balanced against the additional time and volume of solvent required. With respect to the extraction solvent, ethyl-acetate was found to achieve the highest recovery efficiencies. Our results contrast with data obtained using human plasma for example, where diethyl ether was a more effective organic solvent for extracting LNG than ethyl acetate [41].

The extraction efficiency reported in this study is generally comparable to published extraction efficiencies for a

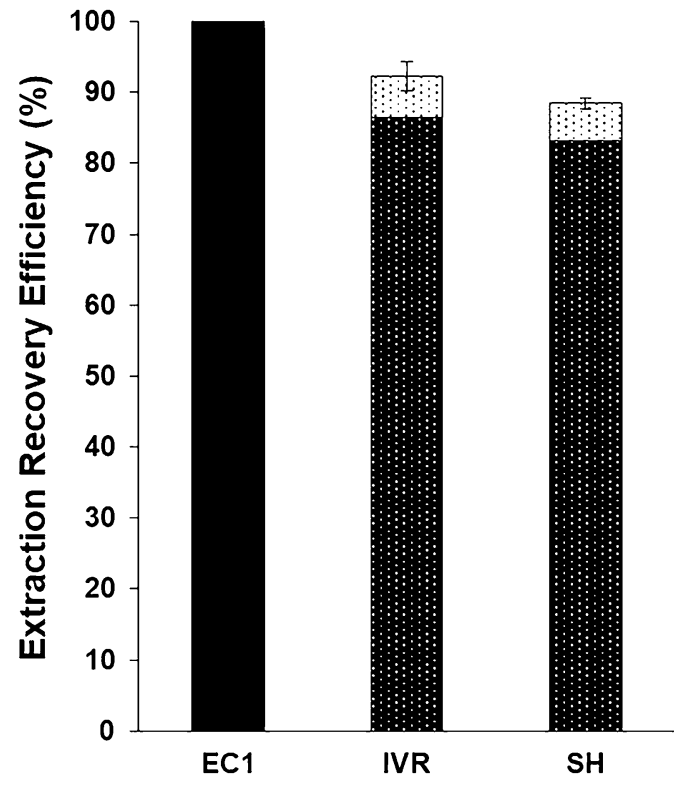

-1st extraction $\boxminus 2$ nd extraction b

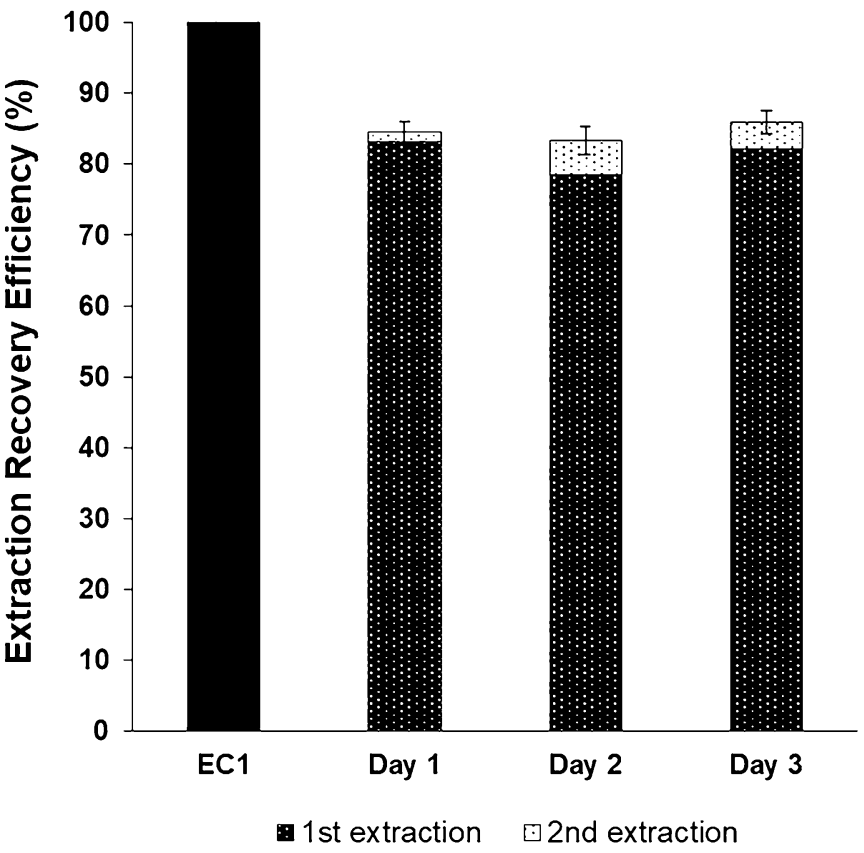

the mean average $\pm \mathrm{SD}(n=3)$. (b) Repeated analysis of the extraction recovery efficiencies of $\mathrm{LNG}$ from spiked $\mathrm{SH}$ medium $(3.6 \mu \mathrm{g} / \mathrm{mL}$ of LNG) compared to EC1. Experiments were repeated daily, in triplicate, for 3 consecutive days and used the optimised two-step extraction procedure (Fig. 1). Data for day 1, day 2 and day 3 is the mean average $\pm \operatorname{SD}(n=3)$ 
Drug Delivery and Translational Research (2022) 12:335-349

345
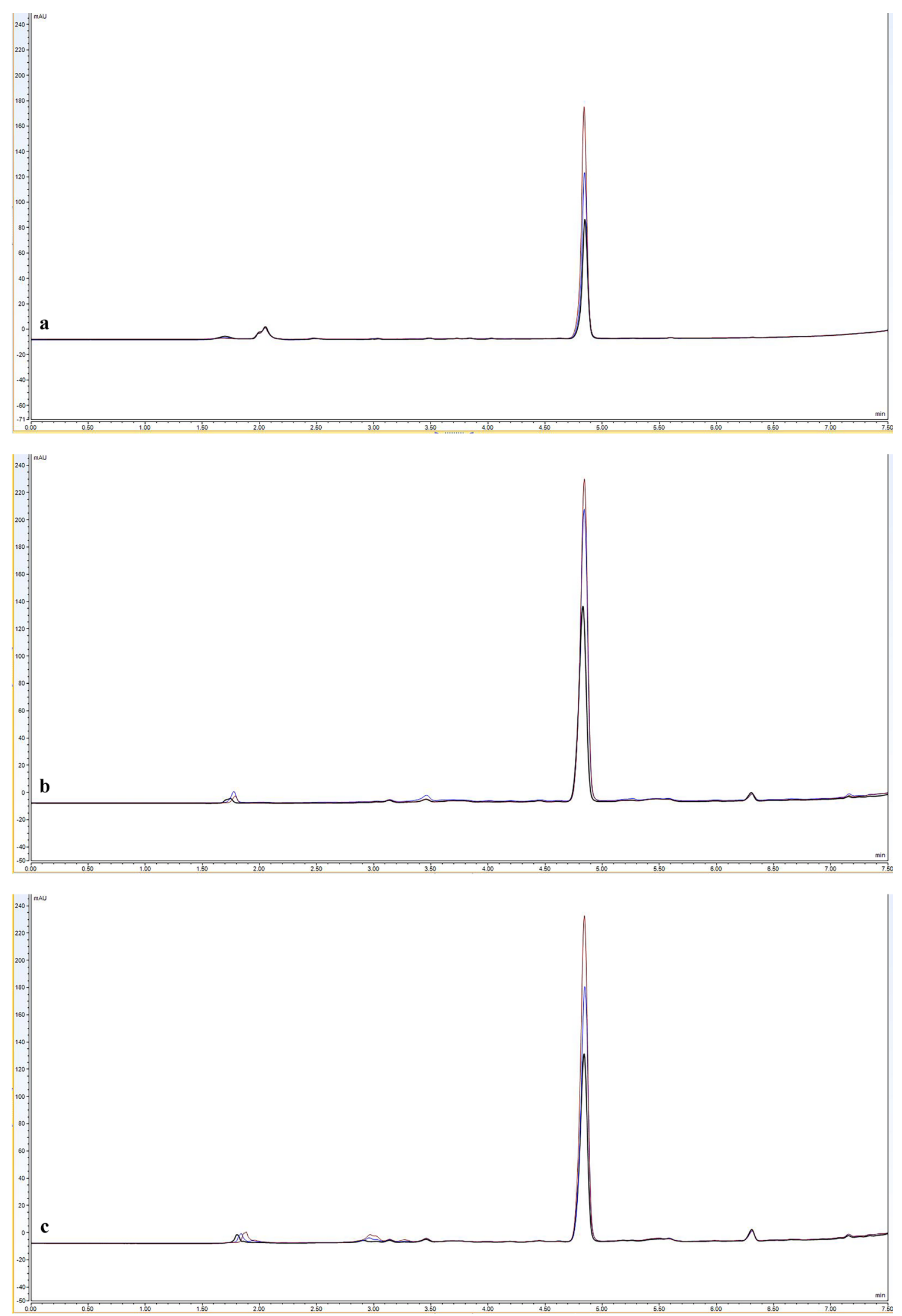

型 Springer 
LNG from human plasma, e.g. 85\% [35] and 84-90\% [33], although one published study achieved a recovery efficiency of $99.5 \%$ [32]. Skin is a highly complex and stratified biological matrix containing collagen fibres, a variety of cell populations and UV-absorbing molecules [58]. Therefore, the analyses of molecules extracted from skin or cutaneous suspensions are particularly challenging, given the necessity for sample pre-treatment to eliminate cutaneous interferent and the requirement to achieve acceptable chromatographic separation.

\section{Evaluation of LNG temporal release in in vitro release medium and ex vivo human skin homogenate medium using a commercially available sustained release formulation}

Jadelle ${ }^{\circledR}$ subcutaneous implants (also known as Norplant II) are a sustained release contraceptive product containing $150 \mathrm{mg}$ of crystalline LNG mixed with dimethyl-siloxane/methylvinylsiloxane copolymer and covered with a rate-limiting silicone membrane. These implants are designed to be surgically inserted into the sub-cutaneous space, typically on the upper arm, and slowly release LNG to provide contraceptive effect up to 5 years [59]. In this study, Jadelle ${ }^{\circledR}$ implants were used to demonstrate whether the supplemented release models (IVR and SH media) and accompanying extraction and analytical methodologies permit the characterisation of LNG release over prolonged periods (Fig. 5).

The chromatograms demonstrate that LNG released from Jadelle $®$ implants maintained a similar retention time to the calibration standards ( $\sim 4.8 \mathrm{~min})$ at all time points over 28 days and in both IVR and SH media, with minimal background interference. As expected, the peak area attributed to LNG increased with time, with the greatest release observed within the first 7 days, due to the acknowledged initial higher 'burst' release profile of Jadelle ${ }^{\circledR}[60]$ (Fig. 5). The chromatograms suggest that there is a small amount of sample contamination from materials emanating from the Jadelle ${ }^{\circledR}$ implant (apparent in all samples at a shorter retention time than the LNG peak) and from the extraction protocol (apparent in samples subjected to the extraction step at a longer retention time than the LNG peak). Whilst any contaminants from the complex SH medium did not appear to significantly interfere with the analytical method (Fig. 5c), it would be important to include a negative control sample of SH medium when conducting quantitative drug release studies to account for potential background interference at the $\mathrm{LNG}$ retention time.

The peak ratios of LNG released in IVR were comparable both without (Fig. 5a) and with (Fig. 5b) the solvent extraction step, indicating that the extraction process does not adversely affect LNG recovery or analysis; the heights and AUCs of these peaks are different as the sample volumes used to load the column are not the same. Equivalent sample volumes were however used in samples derived from LNG extracted from IVR medium (Fig. 5b) and the more complex biological SH medium (Fig. 5c). The peak heights and AUCs derived from these samples were extremely similar, indicating comparable LNG release characteristics in both media. This provides preliminary evidence that IVR medium alone, with the accompanying analytical methodology, could be valuable in rapid, high-throughput pre-clinical screening and optimisation of innovative intradermal sustained release LNG formulations. Further validation work is of course required to ensure that these models are predictive; LNG release studies should be performed to reflect the proposed clinical duration of action and parallel studies should be performed in animal models to determine in vitro-in vivo correlation.

\section{Conclusion}

In vitro (IVR medium) and ex vivo (SH medium) laboratory models of human skin and a robust, rapid, sensitive analytical methodology have been developed, optimised and characterised to determine LNG release from intradermally administered sustained delivery dosage forms. The release models, even when supplemented with a homogenate of excised human skin to improve biological relevance, permit the characterisation of sustained drug release over weeks and months. The analytical method, employing a simple twostep liquid-liquid extraction procedure followed by reversedphase HPLC-UV, is able to accurately quantify nanogram per $\mathrm{mL}$ levels of $\mathrm{LNG}$ and addresses the two main challenges of drug extraction from biological models - recovery of the drug and separation from the diverse biological interferent. In vivo data is now required to further exemplify the utility of the in vitro/ex vivo models and methodology to evaluate emerging intradermal controlled release contraceptive products, such as LNG-loaded biodegradable MNs [13, 14].

Supplementary information The online version contains supplementary material available at https://doi.org/10.1007/s13346-021-01091-5.

Acknowledgements The authors acknowledge the contribution of colleagues at InnoCore Pharmaceuticals (Groningen, The Netherlands) for helpful discussions in developing the in vitro release media and the support of Dr. Maria Dul, Dr. Christopher Thomas and Peter Hansal (at Cardiff University) in developing the analytical assay.

Author contribution AAD, BG, SAC, JCB planned experiments; AAD, $\mathrm{BG}$ performed the experiments and conducted the analyses; $\mathrm{AAD}$, BG, SAC, JCB were involved in manuscript drafting; SAC and JCB obtained project funding. Additional declarations for articles in life science journals that report the results of studies involving humans and/ or animals: All human skin explants/samples were obtained and used under informed written patient consent and local ethical committee approval (LREC Ref: 08/WSE03/55) 
Funding This work is part of a wider collaborative project funded by the Bill \& Melinda Gates Foundation (INV-010030, INV-009575). The authors received the support of the funders and all members of the project consortium. AAD Ph.D. studentship was funded by Cardiff University and Council for At-Risk Academics, UK.

Availability of data and material Access to data will be granted from the authors on reasonable request.

\section{Declarations}

Ethics approval All human skin explants/samples were obtained and used under informed written patient consent and local ethical committee approval (LREC Ref: 08/WSE03/55).

Consent to participate Not applicable.

Consent for publication All the authors consent to publication.

Competing interests The authors declare no competing interests.

Open Access This article is licensed under a Creative Commons Attribution 4.0 International License, which permits use, sharing, adaptation, distribution and reproduction in any medium or format, as long as you give appropriate credit to the original author(s) and the source, provide a link to the Creative Commons licence, and indicate if changes were made. The images or other third party material in this article are included in the article's Creative Commons licence, unless indicated otherwise in a credit line to the material. If material is not included in the article's Creative Commons licence and your intended use is not permitted by statutory regulation or exceeds the permitted use, you will need to obtain permission directly from the copyright holder. To view a copy of this licence, visit http://creativecommons.org/licenses/by/4.0/.

\section{References}

1. Starbird E, Norton M. Investing in family planning: key to achieving the sustainable development goals. Glob Heal Sci Pract [Internet]. 2020;4(2):191-210. Available from: https://doi.org/10.9745/ GHSP-D-15-00374

2. Vrettakos C, Bajaj T. Levonorgestrel. [Updated 2 Mar 2021]. In: StatPearls [Internet]. Treasure Island (FL): StatPearls Publishing. 2021. Available from: https://www.ncbi.nlm.nih.gov/books/NBK539737/

3. Gemzell-danielsson K, Berger C, Lalitkumar PG, Berger C, Lalitkumar PG, Gemzell-danielsson K, et al. Mechanisms of action of oral emergency contraception. Gynecol Endocrinol [Internet]. 2014;3590:8-11. Available from: https://doi.org/10. 3109/09513590.2014.950648

4. Graham S, Fraser IS. The progestogen-only mini pill. Contraception [Internet]. 1982;26(4):373-88. Available from: https:// doi.org/10.1016/0010-7824(82)90104-4

5. Beatty MN, Blumenthal PD. The levonorgestrel-releasing intrauterine system: safety, efficacy, and patient acceptability. Ther Clin Risk Manag [Internet]. 2009;5:561-74. Available from: https://doi.org/10.2147/tcrm.s5624

6. Darney PD. The role of levonorgestrel implants in hormonal contraception. Gynecol Endocrinol [Internet]. 2001;15(sup2):34-40. Available from: http://www.tandfonline. com/doi/full/10.1080/gye.15.s2.34.40

7. Benagiano G, Gabelnick H, Brosens I. Long-acting hormonal contraception. Women's Heal [Internet]. 2015;11(6):749-57. Available from: https://doi.org/10.2217/whe.15.68
8. Waghule T, Singhvi G, Kumar S, Monohar M. Biomedicine \& pharmacotherapy microneedles: a smart approach and increasing potential for transdermal drug delivery system. Biomed Pharmacother [Internet]. 2019;109(July 2018):1249-58. Available from: https://doi.org/10.1016/j.biopha.2018.10.078

9. Hao Y, Li W, Zhou X, Yang F, Qian Z. Microneedles-based transdermal drug delivery systems: a review. J Biomed Nanotechnol [Internet]. 2017;13(12):1581-97. Available from: https://doi.org/10.1166/jbn.2017.2474

10. Ita K. Dissolving microneedles for transdermal drug delivery: advances and challenges. Biomed Pharmacother [Internet]. 2017;93:1116-27. Available from: https://doi.org/10.1016/j. biopha.2017.07.019

11. Guillot AJ, Cordeiro AS, Donnelly RF, Montesinos MC, Garrigues TM, Melero A. Microneedle-based delivery: an overview of current applications and trends. Pharmaceutics [Internet]. 2020;12(569):127. Available from: https://doi.org/10.3390/pharmaceutics12060569

12. Ingrole RSJ, Azizoglu E, Dul M, Birchall JC, Gill HS. PMR Biomaterials Trends of microneedle technology in the scientific literature, patents, clinical trials and internet activity. Biomaterials [Internet]. 2021;267(2020)120-491 Available from: https://doi.org/10.1016/j.biomaterials.2020.120491

13. Path. PATH Microarray Patch Center of Excellence, Linksbridge SPC. Hormonal contraceptive microarray patch: a business case analysis. Seattle: PATH; 2021. [Internet] [cited 14 Apr 2021]. 2021;1-34. Available from: https://path.azureedge.net/ media/documents/PATH_Contraceptive_MAP_Business_Case_ Report_March2021.pdf

14. Paredes AJ, Ramöller IK, Mckenna PE, Abbate MTA, Volpe-zanutto F, Vora LK, et al. Microarray patches: breaking down the barriers to contraceptive care and HIV prevention for women across the globe. Adv Drug Deliv Rev [Internet]. 2021;173:331-48. Available from: https://doi.org/10.1016/j.addr.2021.04.002

15. Kim YC, Park JH, Prausnitz MR. Microneedles for drug and vaccine delivery. Adv Drug Deliv Rev [Internet]. 2012;64(14):154768. Available from: https://doi.org/10.1016/j.addr.2012.04.005

16. Yao G, Quan G, Lin S, Peng T, Wang Q, Ran H, et al. Novel dissolving microneedles for enhanced transdermal delivery of levonorgestrel: in vitro and in vivo characterization. Int J Pharm [Internet]. 2017;534(1-2):378-86. Available from: https://doi.org/ 10.1016/j.ijpharm.2017.10.035

17. Li W, Terry RN, Tang J, Feng MR, Schwendeman SP, Prausnitz MR. Rapidly separable microneedle patch for the sustained release of a contraceptive. Nat Biomed Eng [Internet]. 2019;3(3):220-9. Available from: https://doi.org/10.1038/s41551-018-0337-4

18. Li W, Tang J, Terry RN, Li S, Brunie A, Callahan RL, et al. Longacting reversible contraception by effervescent microneedle patch. Sci Adv [Internet]. 2019;5(11):1-12. Available from: https://doi. org/10.1126/sciadv.aaw8145

19. Zhao X, Zhang S, Yang G, Zhou Z, Gao Y. Exploring trehalose on the release of levonorgestrel from implantable PLGA microneedles. Polymers (Basel) [Internet]. 2020;12(1). Available from: https://doi.org/10.3390/polym12010059

20. He M, Yang G, Zhang S, Zhao X, Gao Y. Dissolving microneedles loaded with etonogestrel microcrystal particles for intradermal sustained delivery. J Pharm Sci [Internet]. 2017;1-9. Available from: https://doi.org/10.1016/j.xphs.2017.11.013

21. Godin B, Touitou E. Transdermal skin delivery: predictions for humans from in vivo, ex vivo and animal models. Adv Drug Deliv Rev [Internet]. 2007;59:1152-61. Available from: https:// doi.org/10.1016/j.addr.2007.07.004

22. Van Ravenzwaay B, Leibold E. Human \& Experimental A comparison between in vitro rat and human and in vivo rat skin absorption Studies. Hum Exp Toxicol [Internet]. 2004;(23):42130. Available from: https://doi.org/10.1191/0960327104ht471oa 
23. Oh L, Yi S, Zhang D, Shin SH, Bashaw E. In vitro skin permeation methodology for over-the-counter topical dermatologic products. Ther Innov Regul Sci [Internet]. 2020;1-8. Available from: https://doi.org/10.1007/s43441-019-00104-3

24. EMA. Guideline on quality of transdermal patches_European Medicines Agency [Internet]. 2014. Available from: https://www. ema.europa.eu/en/documents/scientific-guideline/guideline-qualitytransdermal-patches_en.pdf

25. Yavuz B, Chambre L, Harrington K, Kluge J, Valenti L, Kaplan DL. Silk fibroin microneedle patches for the sustained release of levonorgestrel. Appl Bio Mater [Internet]. 2020;3:5375-82. Available from: https://doi.org/10.1021/acsabm.0c00671

26. Heikkilä M, Haukkamaa M, Luukkainen T. Levonorgestrel in milk and plasma of breast-feeding women with a levonorgestrel-releasing IUD. Contraception [Internet]. 1981;25(1):41-9. Available from: https://doi.org/10.1016/0010-7824(82)90017-8

27. Watson TG, Stewart BJ. A sensitive direct radioimmunoassay for assessing D-norgestrel levels in human plasma. Ann Clin Biochem [Internet]. 1988;25(3):280-7. Available from: https://doi.org/10. 1177/000456328802500316

28. Munro CJ, Laughlin LS, VonSchalscha T, Baldwin DM, Lasley BL. An enzyme immunoassay for serum and urinary levonorgestrel in human and non-human primates. Contraception [Internet]. 1996;54(1):43-53. Available from: https://doi.org/10.1016/ 0010-7824(96)00119-9

29. Kook K, Gabelnick H, Duncan G. Pharmacokinetics of levonorgestrel $0.75 \mathrm{mg}$ tablets. Contraception [Internet]. 2002;66(1):73-6. Available from: https://doi.org/10.1016/S0010-7824(02)00321-9

30. Gainer E, Massai R, Lillo S, Reyes V, Forcelledo ML, Caviedes $\mathrm{R}$, et al. Levonorgestrel pharmacokinetics in plasma and milk of lactating women who take $1.5 \mathrm{mg}$ for emergency contraception. Hum Reprod [Internet]. 2007;22(6):1578-84. Available from: https://doi.org/10.1093/humrep/dem034

31. Wang Q, Wu Z, Wang Y, Luo G, Wu E, Gao X, et al. Determination of levonorgestrel in human serum by liquid chromatographicelectrospray tandem mass spectrometry. Anal Lett [Internet]. 2001;34(1):103-12. Available from: https://doi.org/10.1081/ AL-100002708

32. Theron HB, Coetzee C, Sutherland FCW, Wiesner JL, Swart KJ. Selective and sensitive liquid chromatography-tandem mass spectrometry method for the determination of levonorgestrel in human plasma. J Chromatogr B Anal Technol Biomed Life Sci [Internet]. 2004;813(1-2):331-6. Available from: https://doi.org/ 10.1081/AL-100002708

33. Liu F, Xu Y, Liu A, Xu F, Hu W, Guo Q. LC-tandem-MS validation for the quantitative analysis of levonorgestrel in human plasma. Chromatographia [Internet]. 2008;68(9-10):707-12. Available from: https://doi.org/10.1365/s10337-008-0773-5

34. Moser C, Gschlieer A, Mattle V, Wildt L, Griesmacher A, Seger C. An ultra-sensitive online SPE-LC-MS/MS method for the quantification of levonorgestrel released from intrauterine devices. Anal Bioanal Chem [Internet]. 2011;400(8):2655-62. Available from: https://doi.org/10.1007/s00216-011-4790-0

35. Cirrincione LR, Penchala SD, Scarsi KK, Podany AT, Winchester LC, Back DJ, et al. Development, validation and utilization of a highly sensitive LC-MS/MS method for quantification of levonorgestrel released from a subdermal implant in human plasma. J Chromatogr B Anal Technol Biomed Life Sci [Internet]. 2018;1084(October 2017):10612. Available from: https://doi.org/10.1016/j.jchromb.2018.03.023

36. Tang T, Li P, Luo L, Shi D, Li J, Cao Y. Development and validation of a HPLC method for determination of levonorgestrel and quinestrol in rat plasma. Biomed Chromatogr [Internet]. 2010;24(7):70610. Available from: https://doi.org/10.1002/bmc. 1350

37. Zaidi I, Joshi D, Bhadauria R. Method development and analytical validation of levonorgestrel drug by RP-HPLC method- A Research article. Int J Adv Res Pharm Bio Sci. 2014;4(1):1-10.
38. Ravindra A, Hima P, Swamy KN, Kumar KV. Validated RPHPLC method for simultaneous estimation of levonorgestrel and ethinylestradiol in combined dosage form. J Sci Innov Res. 2013;2(3):598-606.

39. Suhendi A. Validation of high performance of liquid chromatography method for the determination of levonorgestrel and ethinyl estradiol in tablets. J Pharm Sci Res. 2016;8(1):6-9.

40. Zhao L, Zhong G, Bi H, Ding L, Yeng Y, Guan S, et al. Determination of levonorgestrel in human plasma by liquid chromatography-tandem mass spectrometry method: application to a bioequivalence study of two formulations in healthy volunteers. Biomed Chromatogr [Internet]. 2008;22:519-26. Available from: https://doi.org/10.1002/bmc

41. Wang R, Tian Y, Zhang L, Zhang Z. Simultaneous determination of levonorgestrel and two endogenous sex hormones in human plasma based on LC-MS/MS. Bioanalysis [Internet]. 2016;8(11):1133-44. Available from: https://doi.org/10.4155/ bio-2015-0036

42. Zhao X, Birchall JC, Coulman SA, Tatovic D, Singh RK, Wen $\mathrm{L}$, et al. Microneedle delivery of autoantigen for immunotherapy in type 1 diabetes. J Control Release [Internet]. 2016;223:17887. Available from: https://doi.org/10.1016/j.jconrel.2015.12. 040

43. ICH. Validation of analytical procedures: text and methodology. ICH topic Q2(R1). Int Comm Harmon (ICH). 2005;1-17.

44. Ph.Eur. European Pharmacopoeia. Tenth. Strasbourg: European Directorate for the Quality of Medicines \& HealthCare of the Council of Europe (EDQM). 2019;4370.

45. Janagam DR, Wang L, Ananthula S, Johnson JR, Lowe TL. An accelerated release study to evaluate long-acting contraceptive levonorgestrel-containing in situ forming depot systems. Pharmaceutics [Internet]. 2016;8(3). Available from: https://doi.org/ 10.3390/pharmaceutics 8030028

46. Wang SH, Zhang LC, Lin F, Sa XY, Zuo JB, Shao QX, et al. Controlled release of levonorgestrel from biodegradable poly $(\mathrm{D}, \mathrm{L}-$ lactide-co-glycolide) microspheres: in vitro and in vivo studies. Int J Pharm [Internet]. 2005;301(1-2):217-25. Available from: https://doi.org/10.1016/j.ijpharm.2005.05.038

47. Bao Q, Zou Y, Wang Y, Kozak D, Choi S, Burgess DJ. Drug release testing of long-acting intrauterine systems. J Control Release [Internet]. 2019;316(November):349-58. Available from: https://doi.org/10.1016/j.jconrel.2019.11.015

48. Ito Y, Murano H, Hamasaki N, Fukushima K, Takada K. Incidence of low bioavailability of leuprolide acetate after percutaneous administration to rats by dissolving microneedles. Int J Pharm [Internet]. 2011;407(1-2):126-31. Available from: https://doi.org/ 10.1016/j.ijpharm.2011.01.039

49. DeMars Z, Singh VK, Bose JL. Exogenous Fatty Acids Remodel Staphylococcus aureus Lipid Composition through Fatty Acid Kinase. J Bacteriol [Internet]. 2020;202(14):1-16. Available from: https://doi.org/10.1128/JB.00128-20

50. Robins BSP. Metabolism of rabbit skin collagen type-III-collagen precursors determined by constant intravenous. Biochem J [Internet]. 1979;181:75-82. Available from: https://doi.org/10.1042/ bj1810075

51. Camp R, Greaves MW. The catabolism of prostaglandins by rat skin. Biochem J [Internet]. 1980;186(1):153-60. Available from: https://doi.org/10.1042/bj1860153

52. Cao L, Zheng F, Ma P, Liu W, Sun D, Chen X, et al. LC-APCIMS-MS method for the tissue distribution of viaminate after oral administrations to rats. J Chromatogr Sci [Internet]. 2008;46(8):701-6. Available from: https://doi.org/10.1093/ chromsci/46.8.701

53. Ogura M, Paliwal S, Mitragotri S. Sampling of disease biomarkers from skin for theranostic applications. Drug Deliv Transl Res 
[Internet]. 2012;2(2):87-94. Available from: https://doi.org/10. 1007/s13346-012-0061-7

54. Murphy JP, Johnson J, Rainville PD. Enhancing mass spectrometry sensitivity by reducing chromatographic flow rates with Ionkey/Ms. Waters Corp white Pap. 2014;1-6.

55. Bonfilio R, Cazedey ECL, de Araújo MB, Salgado HRN. Analytical validation of quantitative high-performance liquid chromatographic methods in pharmaceutical analysis: a practical approach. Crit Rev Anal Chem [Internet]. 2012;42(1):87-100. Available from: https://doi.org/10.1080/10408347.2012.630926

56. Prasad S, Reddy G, Prasad P, Mukkanti K. Simultaneous HPLC estimation of levonorgestrel and ethinylestradiol from tablets. Indian J Pharm Sci. 2003;231-4.

57. ELISA-kit. Levonorgestrel (LNG) Competitive ELISA Kit [Internet]. [cited 4 Apr 2021]. Available from: https://www.thermofisher. com/elisa/product/Levonorgestrel-LNG-Competitive-ELISA-Kit/ EIALNGC

58. De Paula D, Martins CA, Vitória M, Badra L. Development and validation of HPLC method for imiquimod determination in skin penetration studies. Biomed Chromatogr [Internet]. 2008;1423(July):1416-23. Available from: https://doi.org/10. $1002 / \mathrm{bmc}$

59. FDA. Jadelle (levonorgestrel implants) for subdermal use (Revised: December 2016). US Food Drug Adm. 1996;1-35. Available from: https://www.accessdata.fda.gov/drugsatfda_docs/ label/2016/020544s010lbl.pdf

60. Fuchs R, Taylor D, Jenkins DW, Brache V, Luo D, Dorflinger $\mathrm{LJ}$, et al. Levonorgestrel release rates measured through analysis of two-rod contraceptive explants. Contracept X [Internet]. 2020;2:1-5. Available from: https://doi.org/10.1016/j.conx.2020. 100039

Publisher's Note Springer Nature remains neutral with regard to jurisdictional claims in published maps and institutional affiliations. 